ION IMPLANTED SOLAR CELLS 


\title{
ION IMPLANTED \\ SOLAR CELLS
}

by

J. Bruce Neilson, B.Sc.

\author{
A Thesis \\ Submitted to the Physics Department \\ In Partial Fulfilment of the Requirements \\ for the Degree of \\ Master of Science
}

McMaster University

September 1977 
MASTER OF SCIENCE

(Physics)
MCMASTER UNIVERSITY

Hamilton, Ontario.

TITLE: Ion Implanted Solar Cells

AUTHOR: J. Bruce Neilson, B.Sc. (British Columbia)

SUPERVISOR: Professor J. Shewchun

NUMBER OF PAGES: iv, 43 


\section{ACKNOWLEDGEMENTS}

I wish to thank my supervisor, Dr. J. Shewchun, for his help and guidance in completing this project. I am indebted to T.M. Vanderwel for a great deal of assistance in all phases of the work, especially the planning and design stages, and to R.S. Walker and D.A. Thompson for advice and assistance in the implantation techniques. Finally, I would like to thank all the technicians and graduate students in Dr. Shewchun's research group for their many helpful suggestions and willing technical help whenever it was needed. 


\section{TABLE OF CONTENTS}

List of Tables and Figures

Introduction

Experimental: Solar Cells
A Sample Preparation
6
B Implantation
7
C Final Processing
8
D Testing
9

Experimenta1: Hall Samples

A Sample Preparation 10

B Implantation 10

C Final Processing 11

D Testing 11

Experimental Results 13

Summary 18

$\begin{array}{ll}\text { Tables and Figures } & 20\end{array}$

References 43 


\section{LIST OF TABLES AND FIGURES}

Table 1: List of Implants $\quad 20$

Figure 1: Normal Hall Sample 21

Figure 2: Modified Hall Sample 21

Figure 3: Calculated Dopant Concentration: 22

Sample Plot

Figure 4: Solar Cell Configuration 23

Figure 5: Solar Simulator Spectrum 24

Figure 6: Solar Ce11 Testing System 25

Figure 7: Solar Cel1 Measurement Output Plot 26

Figure 8: Hall Sample Configuration $\quad 27$

Figure 9: Hall Measurement System $\quad 28$

Figure 10: Hall System Step Sequence 29

Figure 11a: Efficiency vs Implant Temperature 30

Figure 11b: Efficiency vs Anneal Temperature 31

Figure 12a: Carrier Concentration vs Anneal Temperature 32

Figure 12b: Hall Mobility vs Anneal Temperature 33

Figure 12c: Hall Sample $0_{m p}$ vs Anneal Temperature 34

Figure 13: Efficiency vs Dopant Concentration 35

Figure 14a: Ha11 Mobility vs Dopant Concentration 36

Figure 14b: Carrier Concentration vs Dopant Concentration 37

Figure 15: Efficiency vs Junction Depth 38

$\checkmark$ Figure 16a: Carrier Concentration vs Junction Depth 39

Figure 16b: Hall Mobility vs Junction Depth 40

Figure 17: Spectral Response at Various Junction Depths 41

Figure 18: Proposed Grating Structure Solar Cell 42 


\section{INTRODUCTION}

A topic of much interest recently is energy production, and one means of production with much to recommend it is the solar cell, a device which converts sunlight directly into electrical energy. In addition to the possible use as a general energy source, solar cells have current uses, including power generation for space stations and satellites, and the powering of remote installations such as weather stations where other power sources are not feasible.

i The solar cell is, in essence, a semiconductor $p-n$ junction with a contact grid on the surface and a low resistance contact covering the bottom. Incident light gemerates electron-hole pairs, some of which diffuse across the junction and generate a voltage across it, and thus a voltage between the top and bottom contacts. The most efficient solar cells currently available ( $10 \%$ to $20 \%$ conversion) are single crystal silicon cells, and it is with these cells that this project is concerned.

A number of different fabrication methods are currently used in the production of single crystal silicon solar cells, including gas and spin-on diffusion techniques, MOS structures and thin film heterojunctions. The purpose of this project is to investigate the feasibility of the use of ion implantation as a fabrication 
method, and to study the effect of implant parameters on solar cell efficiency with a view to optimization.

Much work has been done on the use of implantation doping in the fabrication of devices and integrated circuits. However, little has been done to investigate its potential in the fabrication of solar cells $(1,2)$. Several advantages of the use of ion implantation are apparent. There is greater control of the dopant distribution than with conventional diffusion techniques. In particular, very shallow junctions are possible, allowing the formation of the "blue-shifted" cell ${ }^{(3)}$, which shows an enhanced response to the short wavelength end of the spectrum. This should result in increased efficiency for terrestrial applications, but of more importance for space applications. Also, the geometry control available with the implantation technique facilitates the fabrication of grating cells(4), which also have an enhanced blue response and correspondingly increased terrestrial efficiency possibilities.

In the first part of this project, p-type silicon substrates were implanted with arsenic and phosphorous at energies from $20 \mathrm{keV}$ to $120 \mathrm{keV}$, at implant temperatures from $40^{\circ} \mathrm{K}$ to $300^{\circ} \mathrm{K}$. The samples were vacuum annealed, aluminum contacts were made, and the solar cell efficiencies were measured under a solar simulator.

For the second part of the project, the most significant implants were duplicated in samples in which the carrier concentrations and Hall mobilities at room temperature were measured using the Hall effect. 
The Hall effect is a well known method for measuring the carrier concentration and mobility in a semiconductor. In the discussion that follows n-type extrinsic semiconductor is assumed, although the argument can be extended. A bar shaped sample (see figure 1) of semiconducting material has a fixed current I passed through it between contacts $A$ and $B$, while a magnetic field $B_{z}$ is applied normal to the sample, perpendicular to the plane of the drawing. Conductivity, assuming spherically symmetric band structure, may be defined as $\sigma=\frac{1}{\rho}=\frac{j}{E}$ where $j$ and $E$ are current density and electric field respectively, and $\rho=\frac{1}{\sigma}$ is resistivity. In our sample of figure 1 with dimensions $1, w, d$, we have $j=\frac{I}{w d}$. Measuring the voltage $v_{c}$ between contacts $C$ and $D$ gives $E_{X}=\frac{V_{T}}{T}$ and $\sigma=\frac{I T}{V C W d}$.

We define the Hall mobility $\mu$ as $\mu=\frac{V}{E} x$ where $v_{x}$ is the average electron velocity. In the presence of a magnetic field $B_{z}$ there is a force on the electrons in the $y$ direction of magnitude $\mathrm{qv}_{\mathrm{x}} \mathrm{B}_{z}$ ( $q$ is the electron charge). At equilibrium there must be a transverse electric field $E_{y}$ such that $\quad q E_{y}=q v_{x} B_{z}=q \mu E_{x} B_{z}$. Now $E_{x}=\frac{j}{\sigma}=\frac{I}{w d \sigma}$ and $E_{y}=\frac{V_{h}}{w}$ where $V_{h}$ is the Hall voltage measured between contacts $E$ and $F$ (figure 1 ), hence $\frac{V_{h}}{W}=\frac{\mu I B}{W d \sigma} z \quad$ or $\quad V_{h}=\frac{R I B}{d} z$ where $\quad R=\frac{\mu}{\sigma}$ is called the Hall coefficient. By measuring $V_{h}$ we can calculate $R$, and having previously measured $\sigma$ we can calculate $\mu=$ Ro. 
Finally, since $\sigma=\frac{j}{E}=\frac{q n v}{E} x=q n \mu$

we have concentration of electrons $n=\frac{\sigma}{q \mu}=\frac{1}{q R}$.

Thus by measuring the values of $1, w, d, I, B_{z}, V_{c}$ and $v_{h}$ we can calculate $\mu=R \sigma, \sigma=\frac{1}{\rho}=\frac{I 1}{V_{c} w d}, R=\frac{d V_{h}}{I B_{z}}$ and $n=\frac{1}{q R}$.

A difficulty arises with the samples under study since the carrier concentrations are so high $\left(10^{20} \mathrm{~cm}^{-3}\right)$, yielding very low Hall voltages. A normal Hall sample (figure 1 ) in a magnetic field ideally has conductivity voltage $V_{c}=\frac{I l}{W d}$ and Hall voltage $V_{h}=R \frac{I B}{d} z$. In any real sample, however, the contacts $E$ and $F$ will not be on an exact equipotential 1ine, even in the absence of a magnetic field; there will therefore be a small offset voltage $V_{0}=I R_{0}$ and we will have an error in $V_{h}$. The usual procedure is to reverse $I$ and $B_{z}$ in turn, average the results, and thus cancel out the offset, but in the samples under consideration, at reasonable magnetic field strengths, the Hall voltage may be less than the offset voltage. When this occurs, noise in the offset voltage can completely mask the Hall voltage, making precision very poor, if values can even be obtained, in Hall measurement.

To counteract this effect, the configuration shown in figure 2 was adopted. Here the potentiometer between contacts $F_{1}$ and $F_{2}$ is adjusted to null the offset voltage, then the current and magnetic field were reversed and averaged to remove any remaining offset voltage. This system reduces noise sufficiently to make reproducible readings of the Hall coefficient possible. 
The Hall effect measurements were carried out, and the values of $\mu, n$, and $\rho$ were calculated for the implants done in the second part of the project. These values were related to the results of the solar cell experiments to help explain the variation of the solar cell outputs with implantation parameters. 


\section{EXPERIMENTAL: SOLAR CELLS}

\section{A Sample Preparation}

The substrates used for this work were commercial p-type (B doped) silicon wafers, 111 orientation, with resistivities in the range 0.1 to $10 \mathrm{ohm} \mathrm{cm}$. It was possible that there were variations in quality, but judging from the results these were not significant. Before use the samples were scribed and cleaved into $1 \mathrm{~cm}$ by $1.5 \mathrm{~cm}$ sections, which were then subjected to a standard cleaning procedure as follows:

15 minutes in boiling $\mathrm{H}_{2} \mathrm{SO}_{4}+\mathrm{H}_{2} \mathrm{O}_{2} \quad(2: 1)$

Cool 5 minutes

Rinse thoroughly with de-ionized water

2 minutes in $\mathrm{HF}+\mathrm{H}_{2} \mathrm{O} \quad(1: 10)$

Rinse

15 minutes in boiling $\mathrm{H}_{2} \mathrm{O}+\mathrm{HCl}+\mathrm{H}_{2} \mathrm{O}_{2} \quad(4: 1: 1)$

Rinse and blow dry with $\mathrm{N}_{2}$ gas.

Throughout this procedure the samples were kept within the liquid in a quartz beaker, to avoid contamination by contact with the air. It is believed that the $\mathrm{HCl}$ etch stabilizes the surface after the HF etch activates it, and reduces the adsorption of atmospheric contaminants.

Energies and doses for the implants were calculated to give a uniformly doped surface layer using the data from Gibbons et al ${ }^{(7)}$. The lowest energy ion beam that was easily stabilized was found to be 
$20 \mathrm{keV}$. As can be seen from figure 3 this leaves a very low dapant concentration near the surface, making good ohmic contact to the device difficult. Two possible solutions were found. After the implant a thin surface layer could be removed by growing an oxide $130 \AA$ thick and stripping it in $10 \% \mathrm{HF}$, or a "through-the-oxide" implant could be used to obtain an appreciable impurity concentration at the silicon surface. By comparing the stopping powers of silicon and silicon dioxide, it was found that an oxide thickness of $130 \AA$ would be adequate. This thin oxide could be removed after the annealing procedure. Both methods were tried and were found equivalent, but as the oxidation rate of implanted silicon varies depending on the implant, it was decided that the through-the-oxide implant was preferable. The next step in preparation was therefore to grow an oxide $130 \AA$ thick on the sample. This was done, immediately after cleaning, in a quartz tube three element furnace at $800^{\circ} \mathrm{C}$ in a steam atmosphere. The oxidation time was 19 minutes 10 seconds, which gives an oxide $130 \AA$ thick according to the graph given in Sze ${ }^{(5)}$, page 81 . Sample oxides were measured by ellipsometry and had thicknesses of $140 \pm 10 \AA$.

After oxide growth the samples were moved to the implantation facility, while being handled as little as possible.

\section{B Implantation}

The implantations were done in the $150 \mathrm{keV}$ ion accelerator $(6)$ in the Tandem Accelerator Lab at McMaster. The ion beam is accelerated, 
focussed through a $2 \mathrm{~mm}$ aperture, then electrostatically swept across a second $2 \mathrm{~mm}$ aperture to ensure a uniform implant, and the two apertures were sufficiently off axis to avoid the implantation of neutral impurities. The current on target was 10 to 200 nanoamps swept over an oval $1 \mathrm{~cm}^{2}$ in area; dosimetry was by means of a current digitizer and scalar connected to integrate the target current.

Samples were implanted with several different energies, at doses calculated from the theoretical distributions of Gibbons et al ${ }^{(7)}$ to give uniform concentrations from the silicon-oxide interface to the peak of the deepest implanted layer, and the junction depths were calculated as the intersections of the theoretical implanted concentrations with the background concentrations. An example plot is given in figure 3. Table 1 lists calculated average concentrations and junction depths for various implant conditions.

\section{Final Processing}

The samples require annealing and deposition of aluminum contacts before the solar cells are complete. Annealing was done in a quartz tube three element vacuum furnace at a pressure of $10^{-6}$ torr, at temperatures ranging from $700^{\circ} \mathrm{C}$ to $900^{\circ} \mathrm{C}$. Ten minute isochronal anneals were chosen as sufficient to reach the first annealing plateau commonly observed in silicon annealing ${ }^{(10)}$.

After the anneal the $130 \AA$ oxide window was etched off in $10 \% \mathrm{HF}$ and aluminum contact pads were evaporated on the top and bottom in a 
vacuum evaporator, through a brass mask in the desired design (see figure 4). Finally, the contacts were sintered for 10 minutes at $400^{\circ} \mathrm{C}$ under vacuum in the annealing furnace. Contacts made to an unimplanted sample were tested and showed an ohmic characteristic, with a $1.4 \mathrm{ohm}$ resistance.

\section{D $\quad$ Testing}

The cell efficiencies were determined by measuring the illuminated I-V characteristics. Contact was made to the aluminum contact pads by an indium block below and a copper wire probe held in a micromanipulator on top. Illumination was provided by an Air Mass 2 solar simulator consisting of four 300 watt tungsten-iodine lamps with dichroic filters. The output spectrum is shown in figure 5. Input power to the cell at AM2 is $75 \mathrm{~mW} / \mathrm{cm}^{2}$. The I-V characteristic was measured on a system based on a Hewlett-Packard HP 9820 computer and including a digital voltmeter, programmable power supply, and $x y$ plotter. Figure 6 shows a block diagram of the system and a typical output plot is given in figure 7. Significant values are the open circuit voltage $\left(V_{O C}\right)$, the short-circuit current $\left(I_{S C}\right)$, and the maximum output power $\left(0_{m p}\right)$. The fill factor $C_{f f}$, defined as $0_{m p} / V_{o c} I_{s c}$ is a useful quantity, and the efficiency, $0_{m p}$ divided by total incident power, is the parameter being maximized in this study. The cells were illuminated only in the area of the contact grid (see figure 4) to avoid edge effects and to define the input power.

Dark I-V characteristics were also measured, to give an indication of the quality of the $p-n$ junctions formed. 


\section{EXPERIMENTAL: HALL SAMPLES}

\section{A Sample Preparation}

The same substrate material was used for the Hall samples as for the solar cells, and the same standard cleaning procedure. Sample size was changed to $7 \mathrm{~mm} \times 10 \mathrm{~mm}$. In order to measure the Hall coefficient and resistivity a bar shaped implanted region was required (figure 8 ). The implanted region was defined by protecting the areas not to be implanted with a thick oxide during implantation. Immediately after cleaning the samples were placed in the oxidation furnace at $900^{\circ} \mathrm{C}$ in a steam atmosphere for 105 minutes, growing an oxide $4000 \AA$ thick according to Sze ${ }^{(5)}$ page 81 . A film of Shipley AZ 1350 photoresist was then spun onto the samples at 4000 RPM and pre-baked 5 minutes at $100^{\circ} \mathrm{C}$. The photoresist was then exposed through an image of the implant pattern, developed, and baked for 1 hour at $100^{\circ} \mathrm{C}$. The sample was etched for 4 minutes in $50 \% \mathrm{HF}$ solution to etch the implant window, the remaining photoresist removed with acetone; and the sample rinsed in de-ionized water. Finally a thin oxide was grown, as for the solar cells, in $800^{\circ} \mathrm{C}$ steam for 19 minutes 10 seconds.

\section{B Implantation}

The Hall samples were implanted on the same equipment and in the same manner as the solar cells. 


\section{C $\quad$ Final processing}

The annealing and contact deposition procedures were identical with those used for the solar cells, except that a different brass mask was used for the contact evaporation (figure 8). Note that the oxide etch prior to contact deposition removed only the thin oxide over the Hall bar, leaving the thick oxide over the unimplanted region, thickness slightly reduced, as an insulator over the substrate. This considerably reduces the alignment requirements for the contacts.

Following the $400^{\circ} \mathrm{C}$ sintering step, gold wires were bonded to the contact pads with an ultrasonic wirebonder to facilitate Hall testing.

\section{D $\quad \underline{\text { Testing }}$}

The resistivities and Hall coefficients of the samples were measured at room temperature on a computerized system described in detail by Shewchun et al ${ }^{(8)}$. The system, controlled by a computer sequencer, switched the sample current and the magnetic field through plus and minus values while measuring the Hall voltage. It also measured the conductivity voltage in each direction, the current, the magnetic field, and the sample temperature. Readings can be made automatically at fixed intervals of up to 20 minutes. The data is typed or punched on paper tape as it is measured, and later analysed on a CDC 6400 computer to give calculated values of the Hall coefficient, Hall mobility, carrier 
concentration, and resistivity, using the equations derived in the introduction of this paper.

Figures 9 and 10 show a block diagram of the components of the system and the step sequence followed in the testing of a sample, including the current and field reversal for averaging out the offset voltage.

As a check on the applicability of the Hall tests to the previously done solar cell measurements, the Hall samples were also tested for solar cell output, and these results compared with the efficiencies of the previous part. 


\section{EXPERIMENTAL RESULTS}

Several implantation parameters were varied, and the dependance of the cell performance was studied. Results are given here with cell efficiency as the dependent variable.

Earlier published results ${ }^{(9)}$ have suggested that better electrical activity is obtained by total amorphization of the surface layer during implantation followed by epitaxial regrowth of the damaged region in the anneal stage. It was therefore expected that with low implant temperatures, where little or no annealing occurs during the implantation, a greater amount of damage would accumulate and a more amorphous layer would result, improving the anneal characteristics. This effect was not observed, however, as seen in figure 11(a). All cells are $10 \mathrm{ohm}-\mathrm{cm}$, arsenic implanted to a maximum energy of $80 \mathrm{keV}$, have an average arsenic concentration of $10^{20} \mathrm{~cm}^{-3}$, and were annealed at $800^{\circ} \mathrm{C}$.

The dominant effect in this case was the variation in $I_{s c}$ from $14.5 \mathrm{ma} / \mathrm{cm}^{2}$ at $55^{\circ} \mathrm{K}$ to $20 \mathrm{ma} / \mathrm{cm}^{2}$ at room temperature. Relatively constant $V_{o c}$ and $C_{f f}$ indicate that the barrier formation and sheet conductivity of the surface layer were not greatiy affected by the lower implant temperature, but that the carrier generation rate or lifetime has degraded.

Cells were evaluated after anneals at temperatures ranging from $700^{\circ} \mathrm{C}$ to $900^{\circ} \mathrm{C}$. As shown in figure $11(\mathrm{~b})$, from $700^{\circ} \mathrm{C}$ to $800^{\circ} \mathrm{C}$ cell performance improves with increasing anneal temperature, consistent with 
earlier studies $(9,10)$ showing increasing electrically active fraction of the implanted ions at higher anneal temperatures. Over $800^{\circ} \mathrm{C}$, however, $\mathrm{V}_{\mathrm{OC}}$ drops off accompanied by a less rapid drop in $C_{f f}$.

At first, this reduction in efficiency was attributed to degradation of carrier lifetimes, but this would show up primarily in a lower $I_{\text {sc }}$. The decrease in $V_{\text {oc }}$ suggests a decrease in the junction barrier height, perhaps attributable to an enhanced diffusion resulting in a less abrupt junction.

Hall measurements on duplicate samples yield the interesting result that the carrier concentration shows a curve very similar to the solar cell efficiency (figure 12a). Evidently the annealing proceeds normal1y up to $800^{\circ} \mathrm{C}$, then compensation of some sort begins to occur, and higher anneal temperatures result in lower active impurity concentrations. The mobility seems to anneal out at $750^{\circ} \mathrm{C}$, then degrade very slightly as the temperature increases to $900^{\circ} \mathrm{C}$ (figure $12 \mathrm{~b}$ ).

The loss of cell efficiency because of a lower $V_{\text {oc }}$ would thus appear to be due to a decreased carrier concentration at higher annea] temperatures, which should have exactly the observed effect. The softening of the output response (ie the lower $C_{f f}$ ) can be attributed to a slight increase in sheet resistance of the surface layer associated with this lower carrier concentration.

The solar cell response of these Hall samples was tested under the solar simulator (figure 12c) and is very similar to the curve for the solar cell samples (figure $5 b$ ). 
The effect of both the implanted and the background impurity concentrations on cell efficiency was examined using arsenic implanted cells to a maximum energy of $80 \mathrm{keV}$ at room temperature and annealed at $800^{\circ} \mathrm{C}$. The results are shown in figure 13. It was expected that for greater dopant concentrations on both sides of the junction, the increased barrier height would result in a greater $V_{0 c}$. It is clearly seen in figure 13, however, that the efficiency drops off dramatically when the substrate resistivity is reduced to $0.1 \mathrm{ohm} \mathrm{cm}$. This is probably due to a reduction in carrier lifetimes, resulting in a decreased $I_{S C}$. In a shallow junction cell, the majority of the minority carriers are generated in the bulk material, and so the bulk lifetimes and the surface layer resistivity should be the dominant factors in cell behaviour. The best results would therefore be expected for a cell with a high substrate resistivity, giving long lifetimes, and a high implanted surface concentration to give a low sheet resistance. This is found to be true for diffused cells (11) and, as shown in figure 13, also for implanted cel1s. There may be some depth dependence hidden in these results (see table 1), but the magnitude of this effect over the range of depths here $(600 \AA$ to $1000 \AA)$ should be negligible. Hall tests on the duplicates of these samples showed, as should be expected, a lower carrier concentration and higher mobility in samples which have not been as heavily implanted (figure 14a,b).

There are several ways in which the junction depth can influence the cell efficiency. First, surface effects are less for 
deeper junctions. This reduces the effects of surface recombination, and of small local field perturbations due to inhomogeneities in junction depth and concentration. Also, the sheet resistivity of the surface layer, and therefore the series collection resistance, is lower for a thicker implanted surface layer. This should appear as an increased $\mathrm{C}_{\mathrm{ff}}$. This behaviour is observed in figure 15. Hall measurements (figure 16a) show constant concentration at all depths for the arsenic implants, indicating good reproducibility in the implant conditions. There is a depth dependence in the phosphorus data, but the cause of it has not been determined. It may be due to errors in the predicted depth distributions for phosphorus, and warrants further study, which time does not allow in this project.

The Hall mobility is observed to decrease with increasing depth (figure 16b), which is probably the result of the increased damage to the surface layer by the deeper implants. As has already been noted, the mobility tends to increase as the dose, and thus the damage, decreases.

The monotonic increase with depth of cell efficiency in the arsenic cells suggested the use of phosphorus in order to obtain a deeper junction than was possible with arsenic. It had at first been thought that the good match of the arsenic covalent radius with that of silicon would reduce the strain on the crystal structure at higher doping levels, increasing the carrier lifetime. Phosphorus, however, with its smaller radius, seems to give a better cell, even at the same calculated junction depth, and even higher efficiencies are possible with deeper junctions (see figure 15). Another cell characteristic dependent on junction depth is its 
spectral response. The optical absorption coefficient for silicon increases with increasing photon energy (14), leading to the absorption of most of the blue end of the spectrum very near the surface of the cel1. The result is an enhanced blue response for the shallower junctions. Figure 17 shows the normalized spectral response (based on $I_{S C}$ ) of four cells implanted with arsenic at room temperature and annealed at $800^{\circ} \mathrm{C}$. Impurity concentration is a uniform $10^{20} \mathrm{~cm}^{-3}$ for each cell. The four curves were normalized to coincide at $7000 \AA$. It should be noted that although the shallower junctions showed a higher relative blue response, the overall cell efficiencies followed the behaviour shown in figure 15, that is, the deeper junctions had higher efficiencies. 


\section{SUMMARY}

The use of ion implantation as a solar cell fabrication technique has been investigated. Most of the parameters which could be adjusted were studied, and some progress was made toward the optimization of cell efficiency. It was found that:

1 Low temperature implants do not improve the electrical characteristics of the cell.

2 Optimum annealing was found at $800^{\circ} \mathrm{C}$. Below $800^{\circ} \mathrm{C}$, incomplete activation occurs, and above $800^{\circ} \mathrm{C}$ compensation begins to take place.

$\underline{3}$ The best doping combination was found to be a high implanted concentration $\left(10^{20} \mathrm{~cm}^{-3}\right)$ for low sheet resistivity, and a low substrate impurity concentration $\left(10^{15} \mathrm{~cm}^{-3}\right)$ for long carrier 1ifetimes.

4 As junction depth is increased to $3000 \AA$, cell efficiency increases, but the enhanced blue response of the shallow junction cells is lost.

Optimizing the above criteria as outlined allows the fabrication of reproducable cells of $7 \%$ efficiency, without the use of an antireflection coating or an improved bottom contact, which is comparable to current commercial standards.

The trade-off expressed in point 4 above has led to the proposed use of the grating structure solar cel1 ${ }^{(3)}$. It is suggested that by 
implanting deep stripes and leaving the surface in between undamaged, as shown in figure 18 , the advantages of the increased blue response can still be obtained without the decreased efficiency of the shallow junction ce11. In this way the longer bulk diffusion lengths are used to best advantage, without sacrificing efficient collection.

It is concluded that the use of ion implantation as a solar cell fabrication technique is indeed feasible, either for the planar or grating structure outlined here. Future work along these lines can be started from the point at which this report leaves off. 
TABLE I

\begin{tabular}{|c|c|c|c|c|c|c|c|c|c|c|c|}
\hline Species & $\begin{array}{c}\mathrm{C}_{\mathrm{B}} \\
\left(\mathrm{cm}^{-3}\right)\end{array}$ & $\underset{(\mathrm{keV})}{E}$ & $\begin{array}{c}\$ \\
\left(\mu \mathrm{c}-\mathrm{cm}^{-2}\right)\end{array}$ & $E$ & $\phi$ & $E$ & $\phi$ & $E$ & $\$$ & $\begin{array}{l}C_{A \cup E} \\
\left(\mathrm{~cm}^{-3}\right)\end{array}$ & $\begin{array}{c}D_{j} \\
0 \\
(\AA)\end{array}$ \\
\hline As & $10^{15}$ & 20 & 0.15 & 40 & 0.25 & 80 & 0.42 & & & $10^{18}$ & 870 \\
\hline As & $10^{15}$ & 20 & 1.5 & 40 & 2.5 & 80 & 4.2 & & & 7079 & 930 \\
\hline As & $10^{75}$ & 20 & 15 & 40 & 25 & 80 & 42 & & & 1020 & 1000 \\
\hline As & $2 \times 10^{16}$ & 20 & 0.15 & 40 & 0.25 & 80 & 0.42 & & & $10^{18}$ & 775 \\
\hline As & $2 \times 10^{16}$ & 20 & 1.5 & $40^{\circ}$ & 2.5 & 80 & 4.2 & & & 1079 & 850 \\
\hline As. & $2 \times 10^{76}$ & 20 & 15 & 40 & 25 & 80 & 42 & & & $10^{20}$ & 970 \\
\hline As & $5 \times 70^{17}$ & 20 & 0.15 & 40 & 0.25 & 80 & 0.42 & & & $10^{18}$ & 600 \\
\hline As & $5 \times 10^{77}$ & 20 & 1.5 & 40 & 2.5 & 80 & 4.2 & & & $10^{79}$ & 740 \\
\hline As & $5 \times 10^{17}$ & 20 & 75 & 40 & 25 & 80 & 42 & & & $10^{20}$ & 825 \\
\hline As & $10^{75}$ & 20 & 75 & & & & $\cdots$ & & & $10^{20}$ & 340 \\
\hline As & $10^{15}$ & 20 & 75 & 40 & 25 & & & & & $10^{20}$ & 570 \\
\hline As & $10^{15}$ & 20 & 15 & 40 & 25 & 80 & $42^{\circ}$ & & & $10^{20}$ & 7000 \\
\hline As & $10^{75}$ & 20 & 75 & 40 & 25 & 80 & 42 & 120. & 55 & $10^{20}$ & 1400 \\
\hline P & $10^{15}$ & 20 & 40 & & & & & & & $10^{20}$ & 700 \\
\hline $\mathrm{p}$ & $10^{75}$ & 20 & 25 & 40 & 62 & & 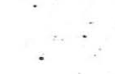 & & & $10^{20}$ & 1300 \\
\hline $\mathrm{P}$ & $10^{15}$ & 20 & 25 & 40 & 28 & 60 & 88 & & & $10^{20}$ & 1800 \\
\hline $\mathrm{P}$ & 1075 & 20 & 25 & 40 & 48 & 80 & 115 & & & $10^{20}$ & 2400 \\
\hline $\mathrm{P}$ & $10^{75}$ & 20 & $25 \cdots$ & 40 & 35 & 60 & 62 & 100 & 135 & $70^{20}$ & 3000 \\
\hline
\end{tabular}

Table 1: List of Implants

$C_{B}$ is substrate carrier concentration. $C_{A V E}$ is average implanted concentration. $D_{j}$ is junction depth calculated from Gibbons et al ${ }^{(7)}$. 


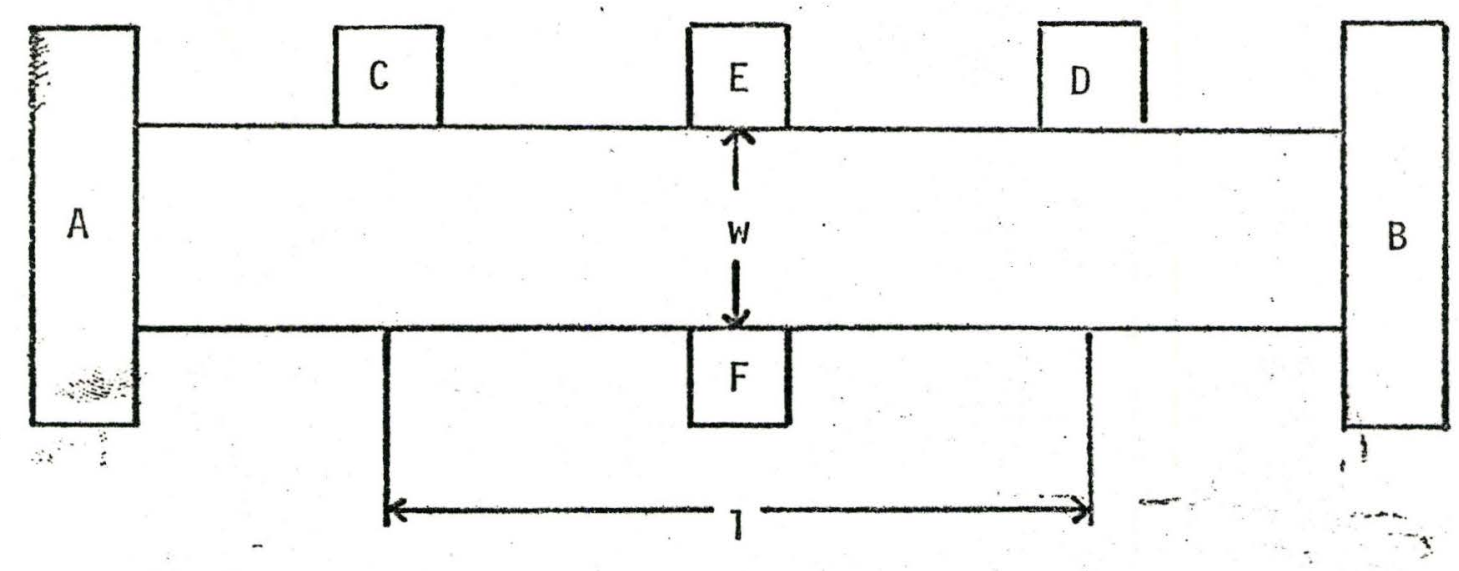

FIGURE 1: Normal Hall Sample

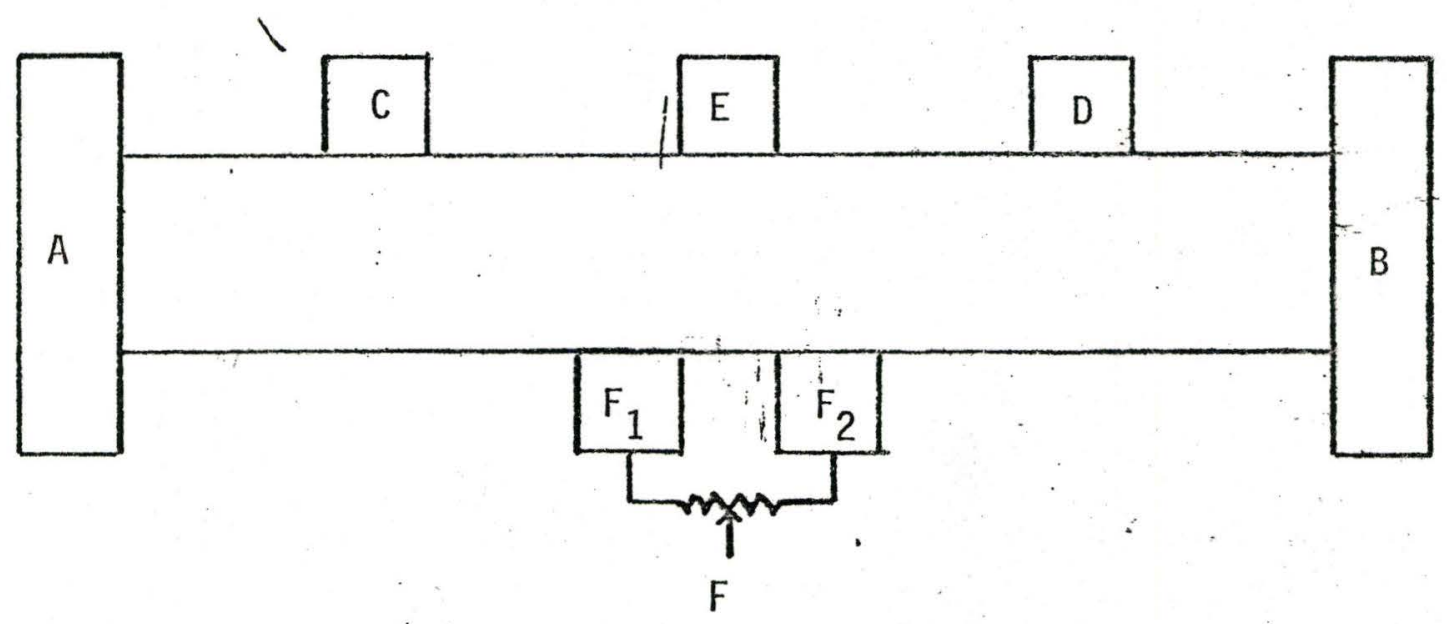

FIGURE 2: Modified Hall Sample 


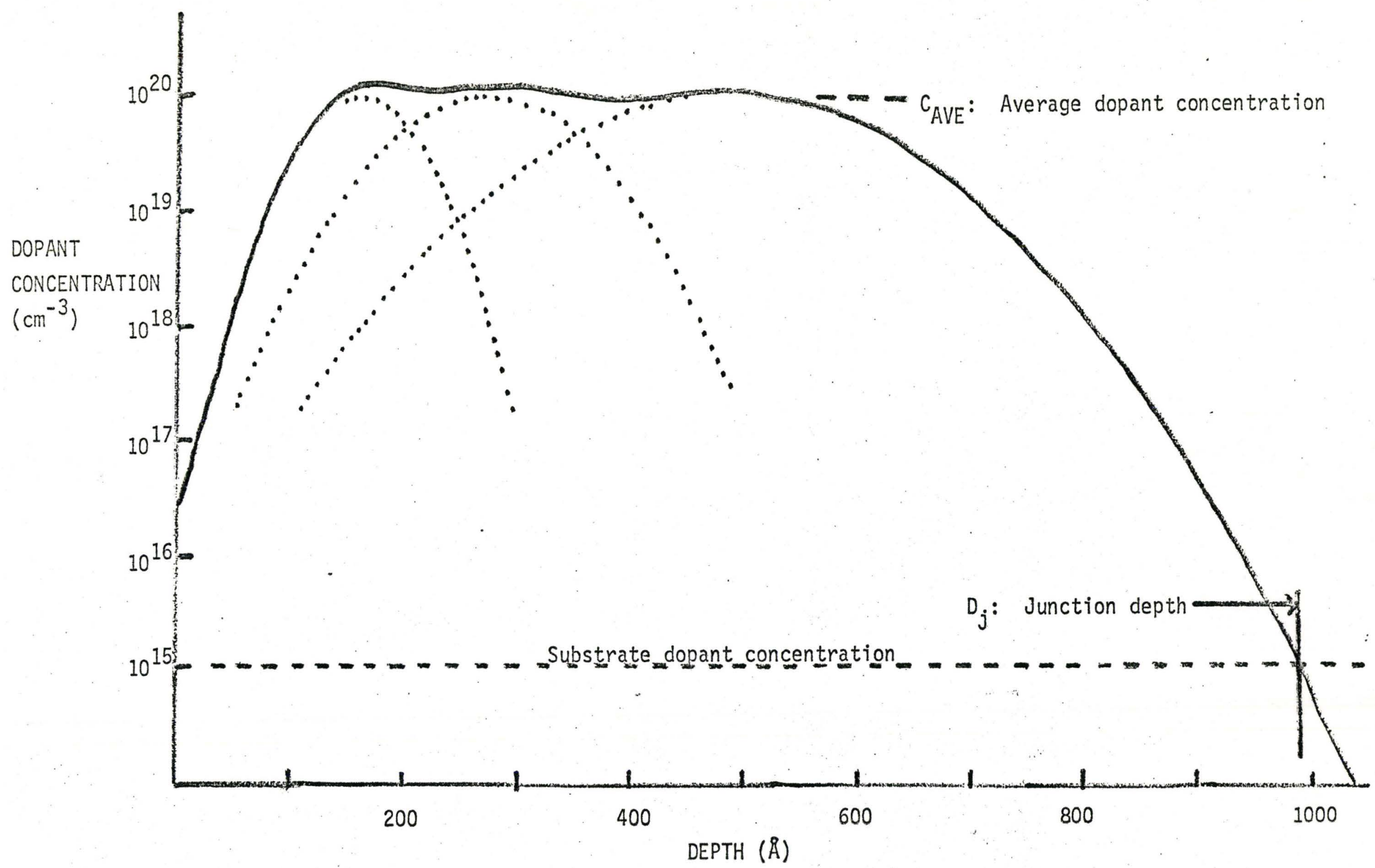

FIGURE 3: Calculated Dopant Concentration: Sample Plot

For arsenic implants of $15 \mu \mathrm{C} / \mathrm{cm}^{2}$ at $20 \mathrm{keV}, 25$ at $40 \mathrm{keV}$, and 42 at $80 \mathrm{keV}$.

Curve parameters ifrom Gibbons et al $(7)$ 


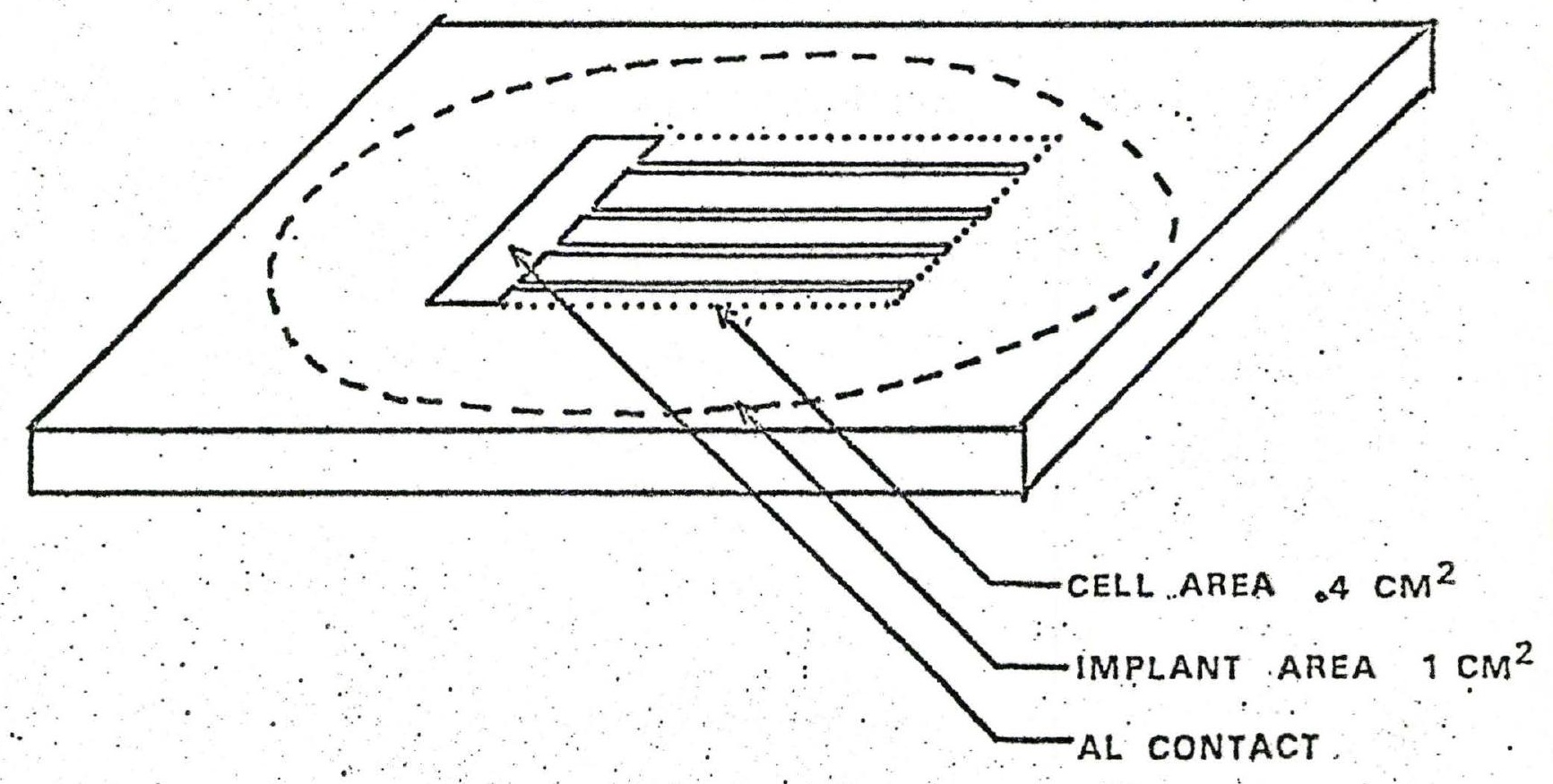

FIGURE 4 : Solar Ce11 Configuration 


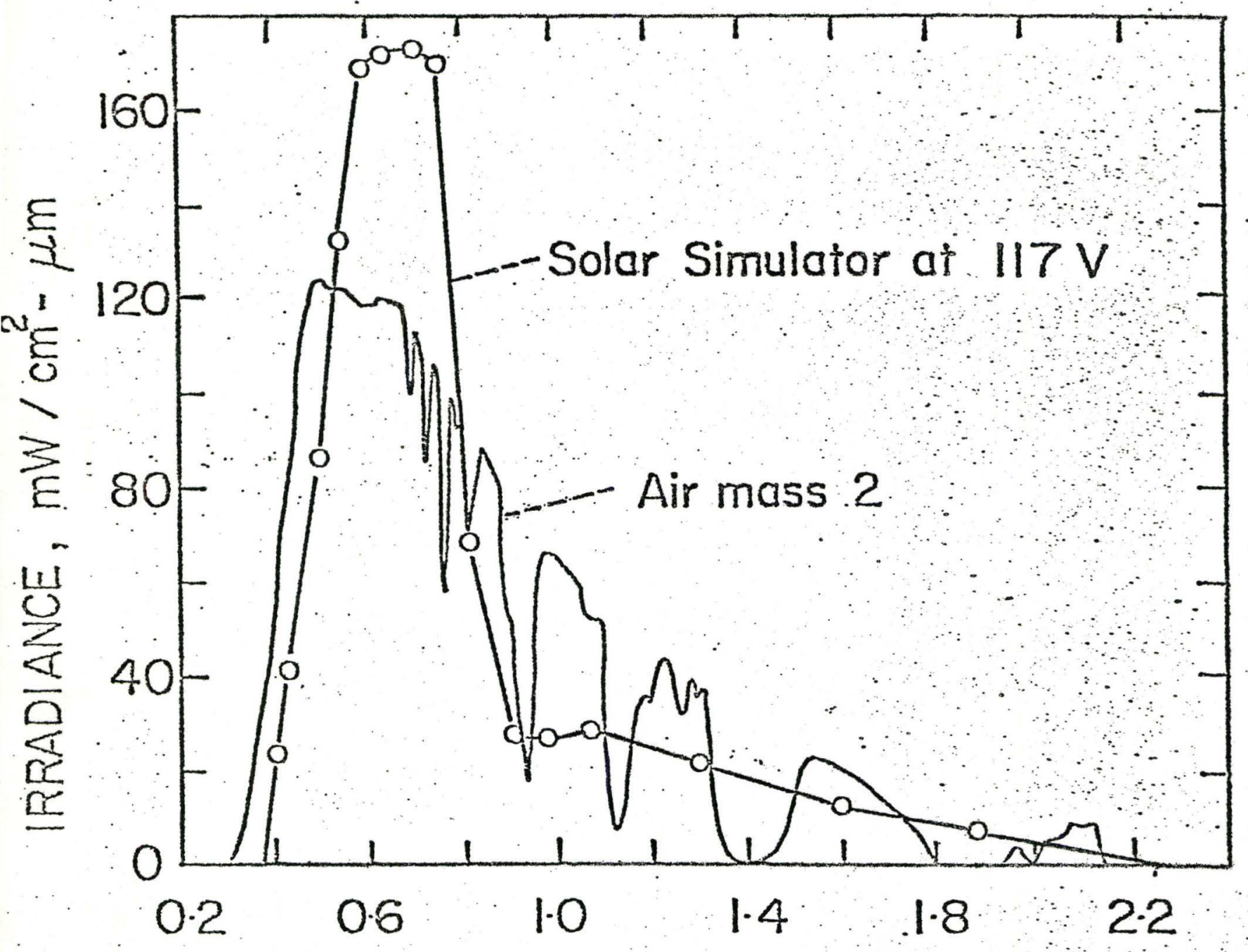

WAVELENGTH $\mu \mathrm{m}$.

FIGURE 5: Solar Simulator Spectrum 


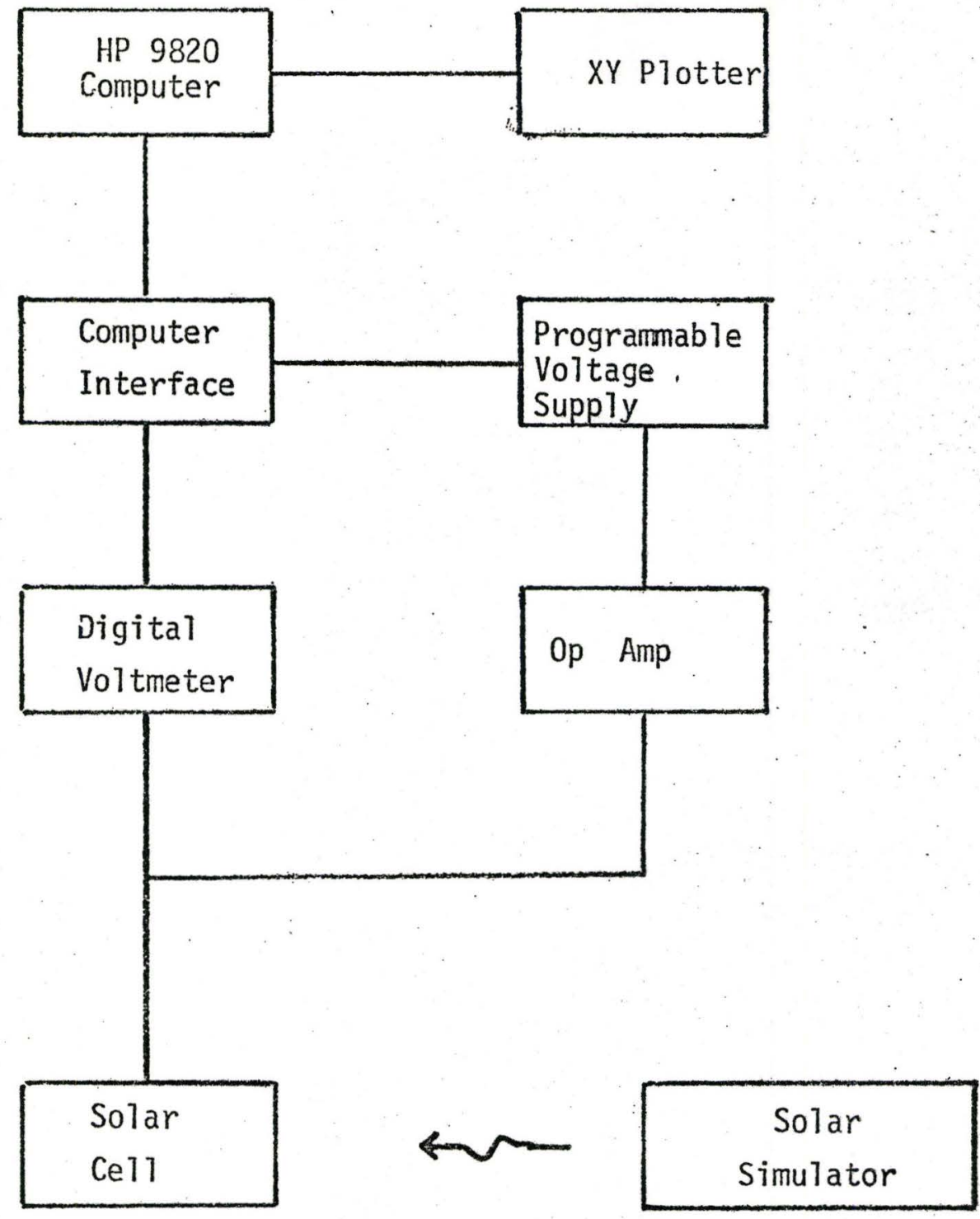

FIGURE 6: Solar Cell Testing System 


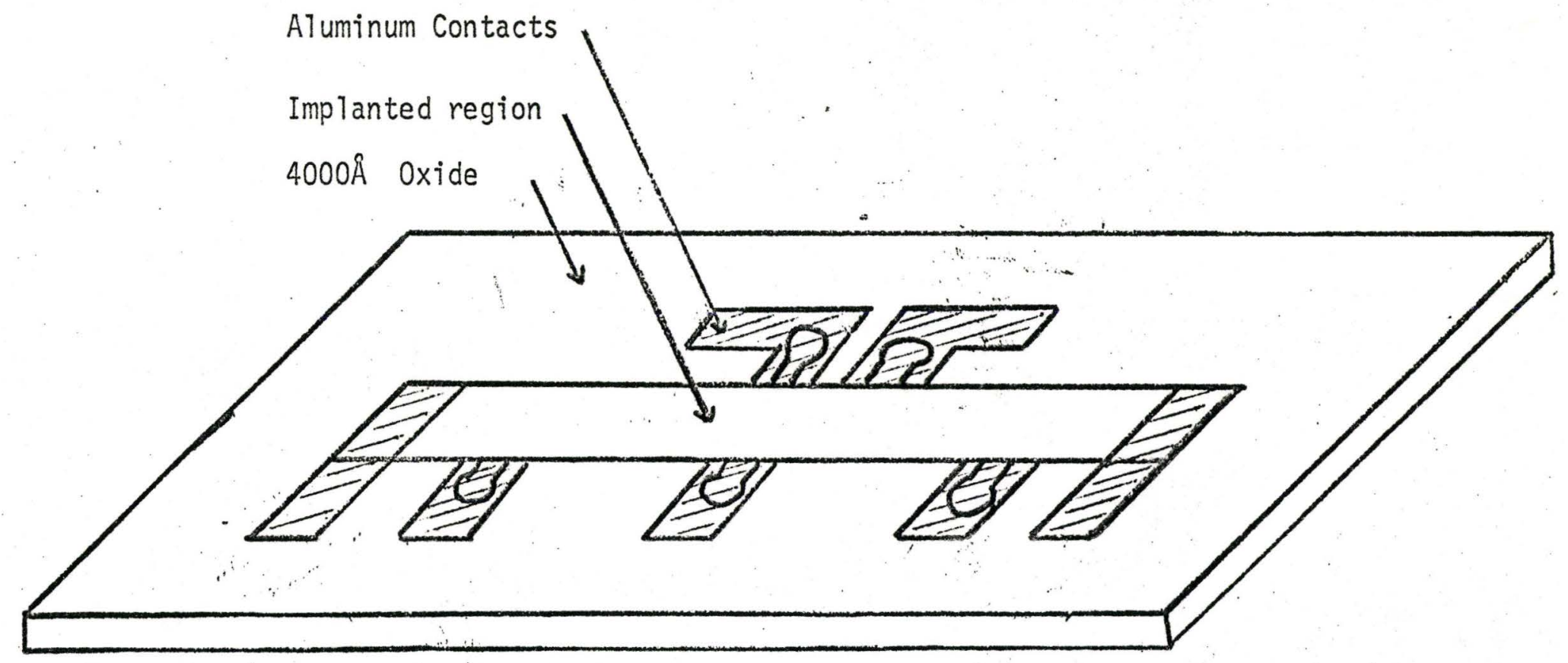

....

FIGURE 8: Hall Sample Configuration 


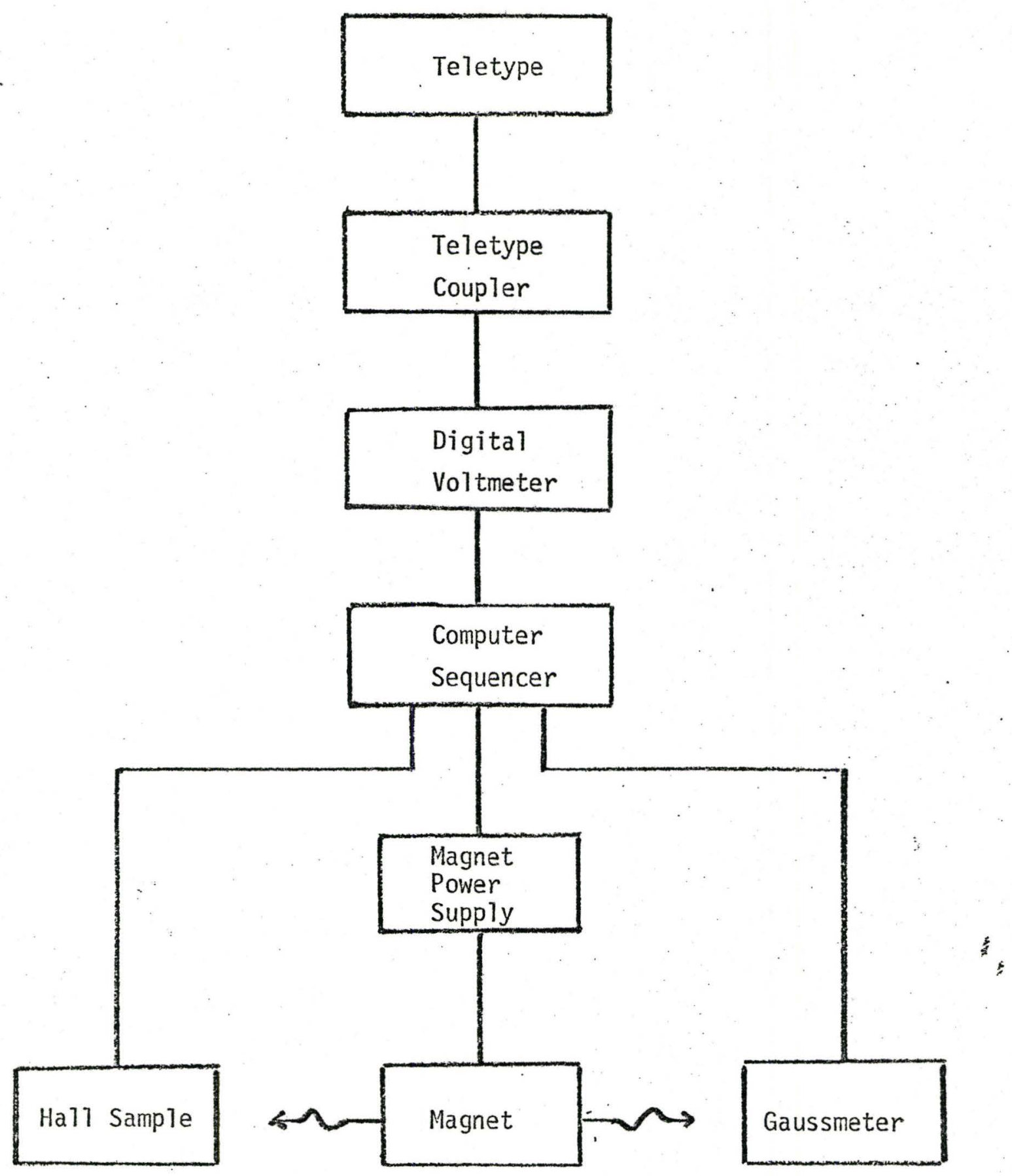

FIGURE 9: Hall Measurement System 
Select sample current indicator

2 Record sample current

Select sample thermometry

4

Record sample temperature

5

Select conductivity contacts

6

Record $V_{c}$

$\left(\mathrm{I}^{+}\right)$

Reverse sample current

8 Record $V_{c}$

$\left(I^{-}\right)$

9 Turn on magnet, select gaussmeter contacts

10 Record magnetic field $\left(\mathrm{B}^{+}\right)$

11 Reverse sample current, select thermometry

12 Record sample temperature

13 Select Hall voltage contacts

14

Record $\mathrm{V}_{\mathrm{h}}\left(\mathrm{I}^{+}, \mathrm{B}^{+}\right)$

15

16

Reverse sample current $\left(\mathrm{I}^{-}\right)$

Record $v_{h}\left(I^{-}, B^{+}\right)$

Turn on magnet with reversed field, reverse sample current $\left(\mathrm{I}^{+}\right)$

Select Hall voltage contacts

20

21

Record $V_{h}\left(I^{+}, B^{-}\right)$

22

Reverse sample current $\left(\mathrm{I}^{-}\right)$

23

Record $V_{h}\left(I^{-}, B^{-}\right)$

24

Shut down magnet

25

Select thermometry

26

Record sample temperature

Adjust sample current. Wait 0 to 20 minutes.

FIGURE 10: Hal1 System Step Sequence 


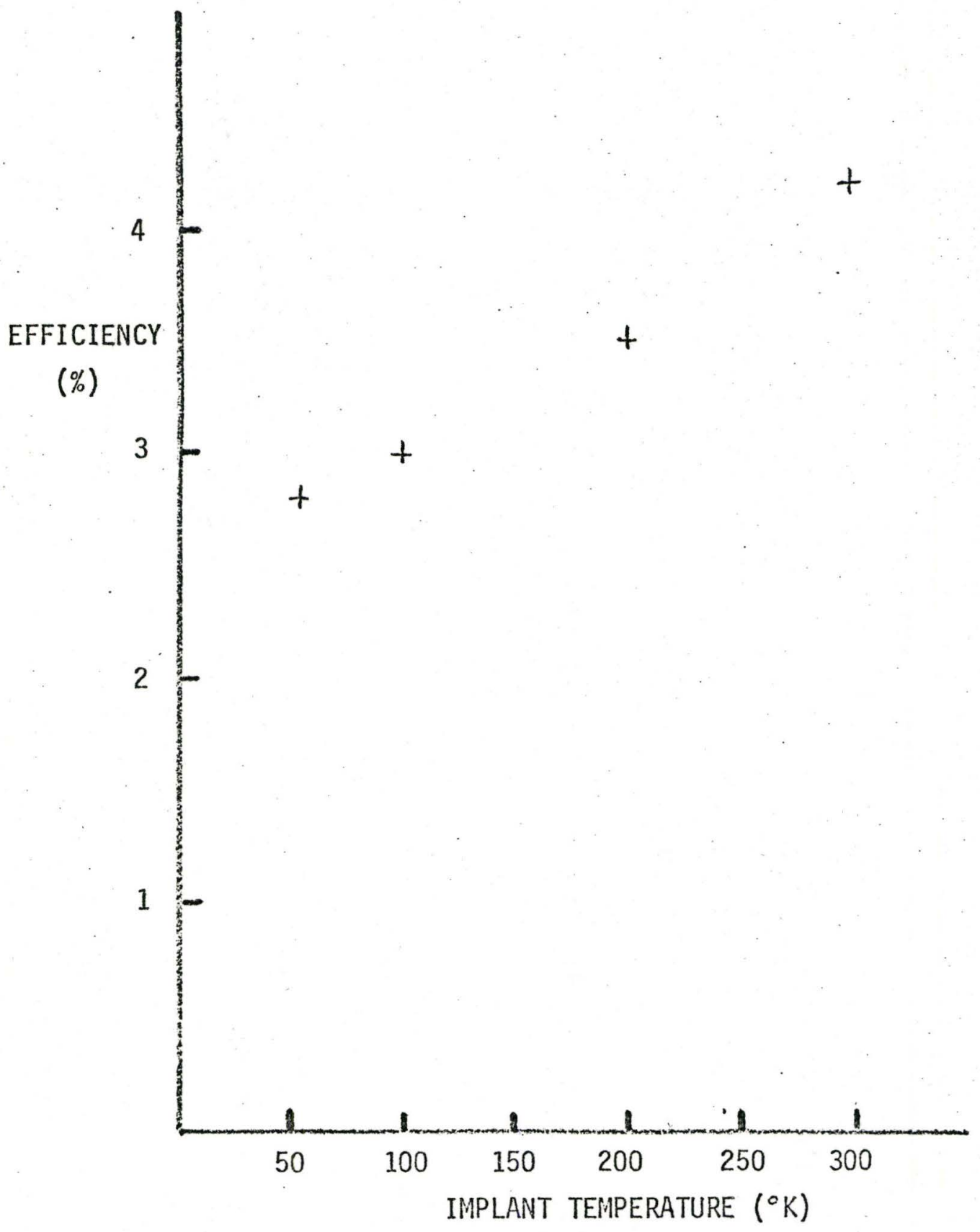

FIGURE 11(a): Efficiency vs Implant Temperature $80 \mathrm{keV}$ arsenic in $10 \mathrm{ohm}-\mathrm{cm}$ silicon. Concentration $10^{20} \mathrm{~cm}^{-3}$ Anneal temperature $800^{\circ} \mathrm{C}$. 


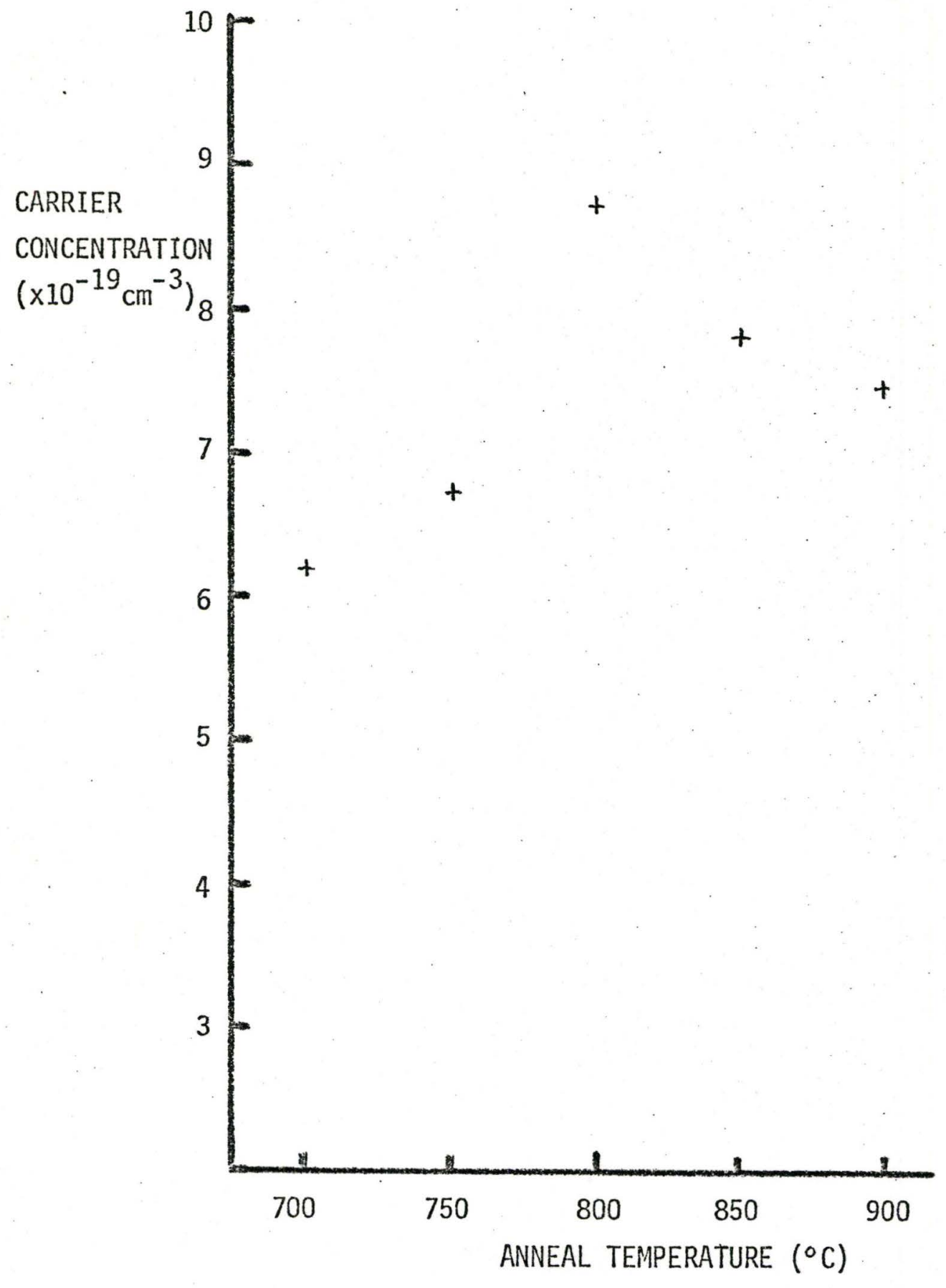

FIGURE 12(a): Carrier Concentration vs Anneal Temperature $80 \mathrm{keV}$ arsenic in $10 \mathrm{ohm}-\mathrm{cm}$ silicon. Implant Temperature $20^{\circ} \mathrm{C}$. 


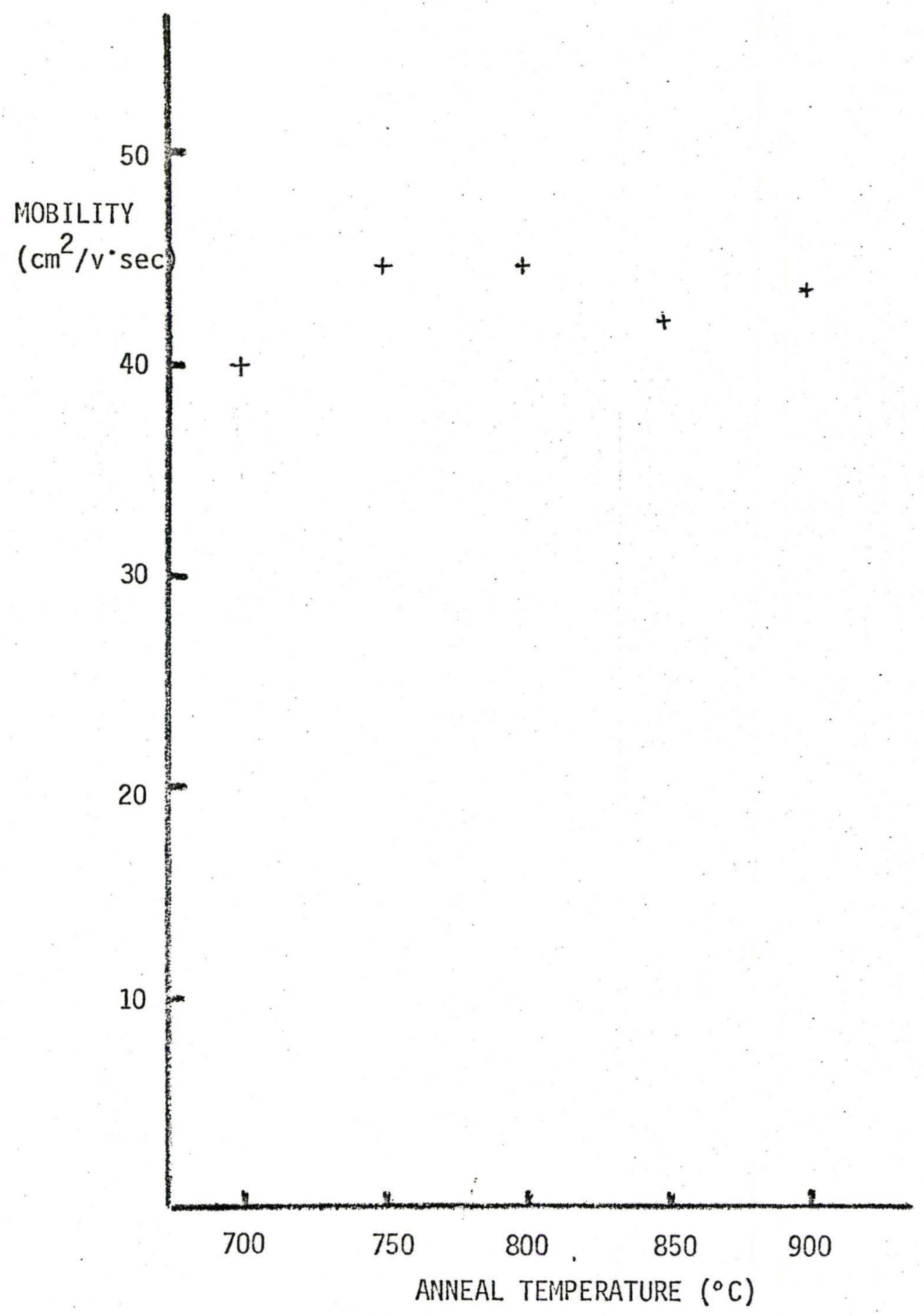

FIGURE 12(b): Mobility vs Anneal Temperature Samples as in figure $12(a)$. 


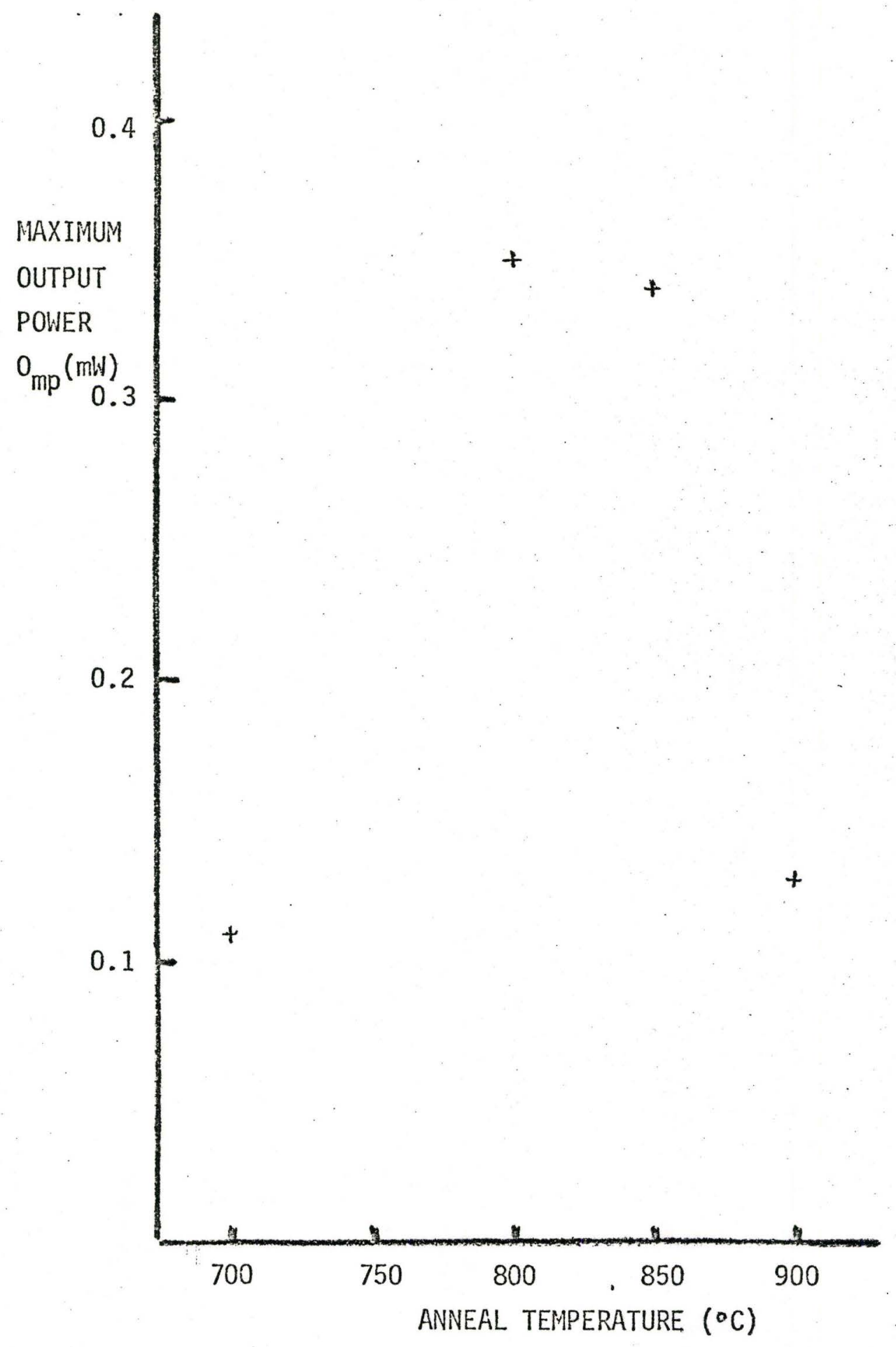

FIGURE 12(c): Hall Sample $0_{m p}$ vs Anneal Temperature Samples as in figure $12(a)$. 


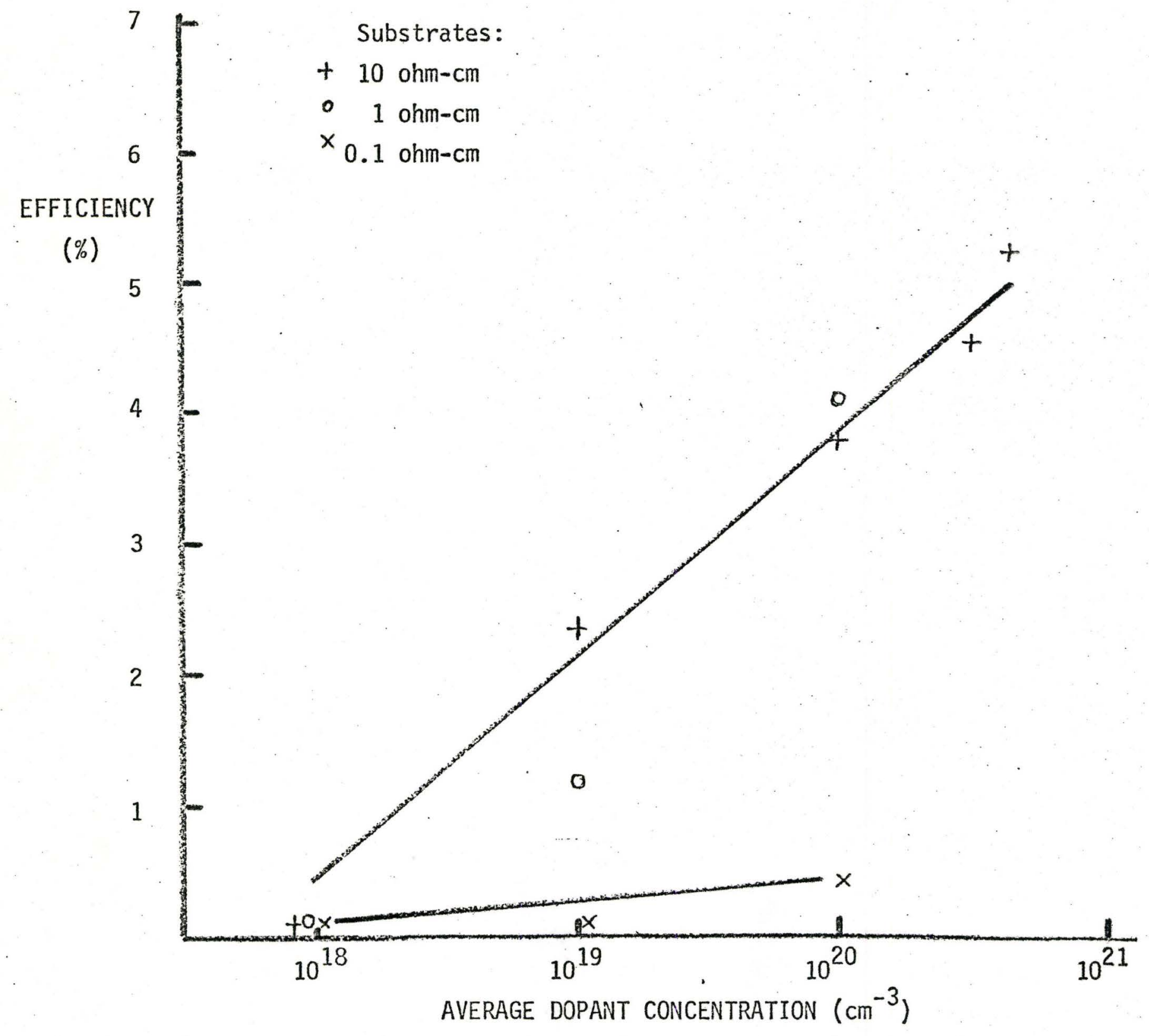

FIGURE 13: Efficiency vs Dopant Concentration $80 \mathrm{keV}$ arsenic in silicon. Implant temperature $20^{\circ} \mathrm{C}$. Anneal temperature $800^{\circ} \mathrm{C}$. 




FIGURE 14(a): Hall Mobility vs Dopant Concentration $80 \mathrm{keV}$ arsenic into silicon. Implant temperature $20^{\circ} \mathrm{C}$. Anneal temperature $800^{\circ} \mathrm{C}$. 


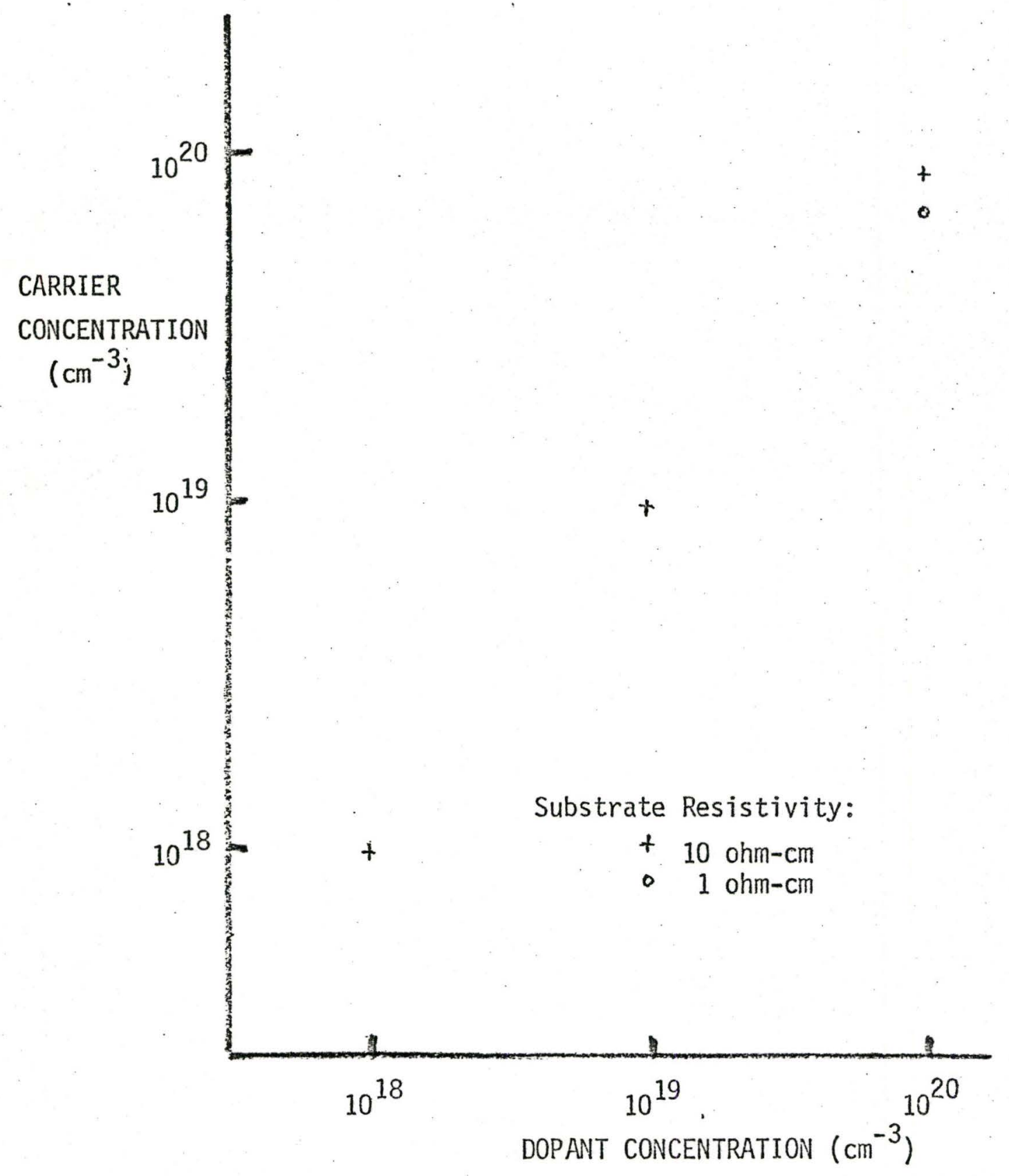

FIGURE 14(b): Carrier Concentration vs Dopant Concentration Samples as in figure 14(a). 


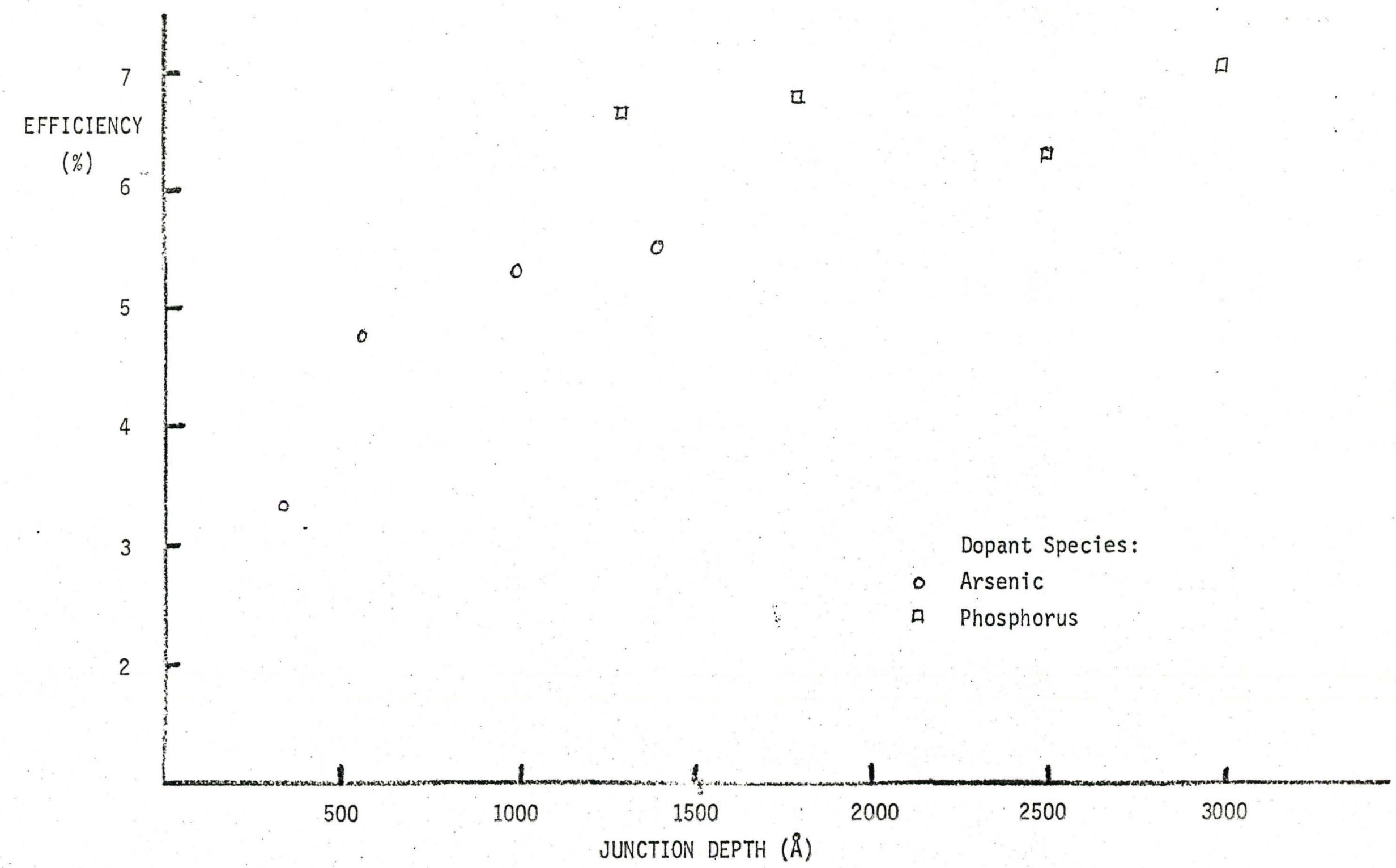

FIGURE 15: Efficiency vs Junction Depth

Dopant concentration $10^{20} \mathrm{~cm}^{-3}$. Implant temperature $20^{\circ} \mathrm{C}$. Anneal temperature $800^{\circ} \mathrm{C}$. Substrate $10 \mathrm{ohm}-\mathrm{cm}$ silicon. Depths from Gibbons et al ${ }^{(7)}$. 


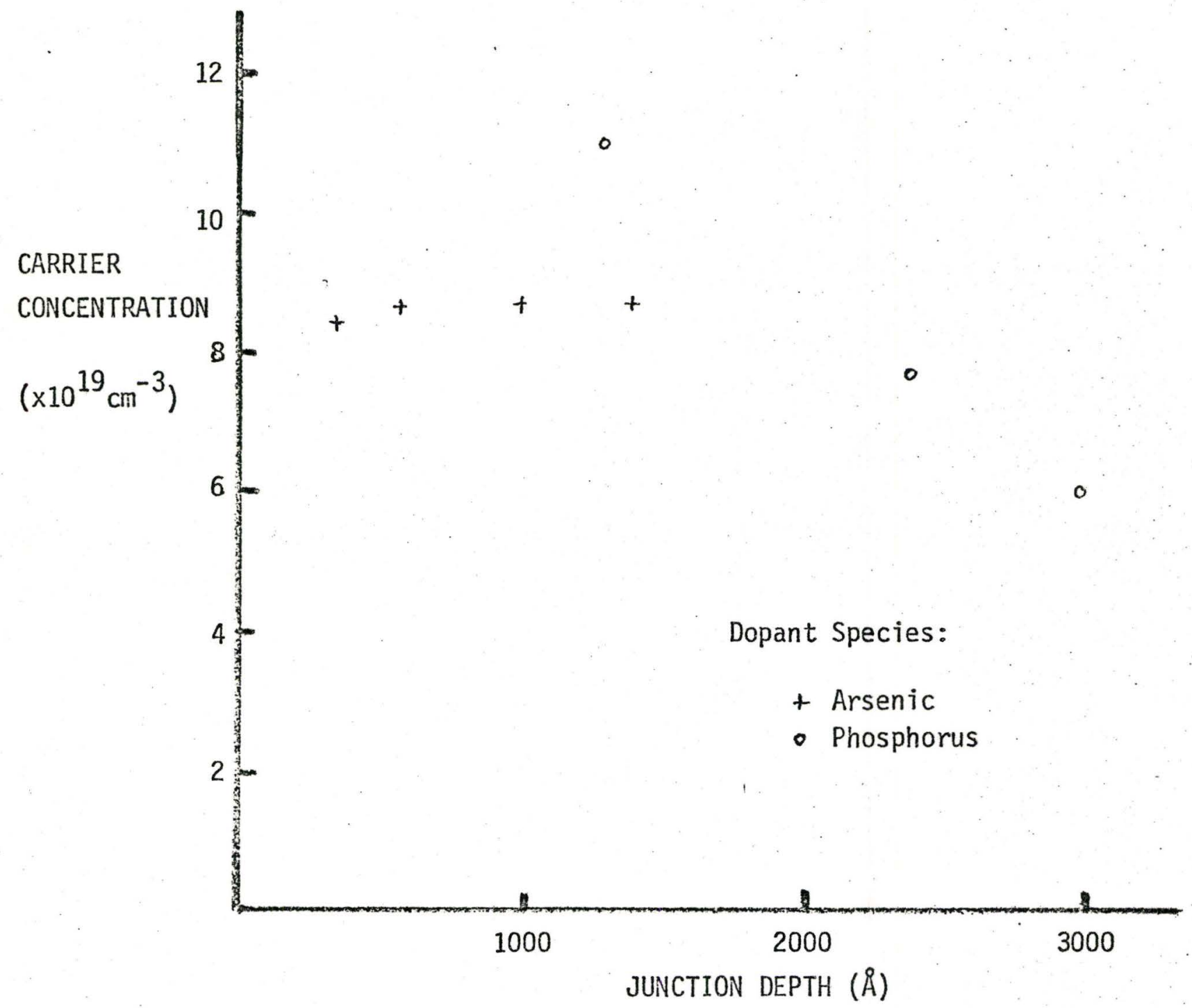

FIGURE 16(a): Carrier Concentration vs Junction Depth Substrate 10 ohm-cm silicon. Implant Temperature $20^{\circ} \mathrm{C}$. Anneal temperature $800^{\circ} \mathrm{C}$. Depths from Gibbons et al ${ }^{(7)}$. 


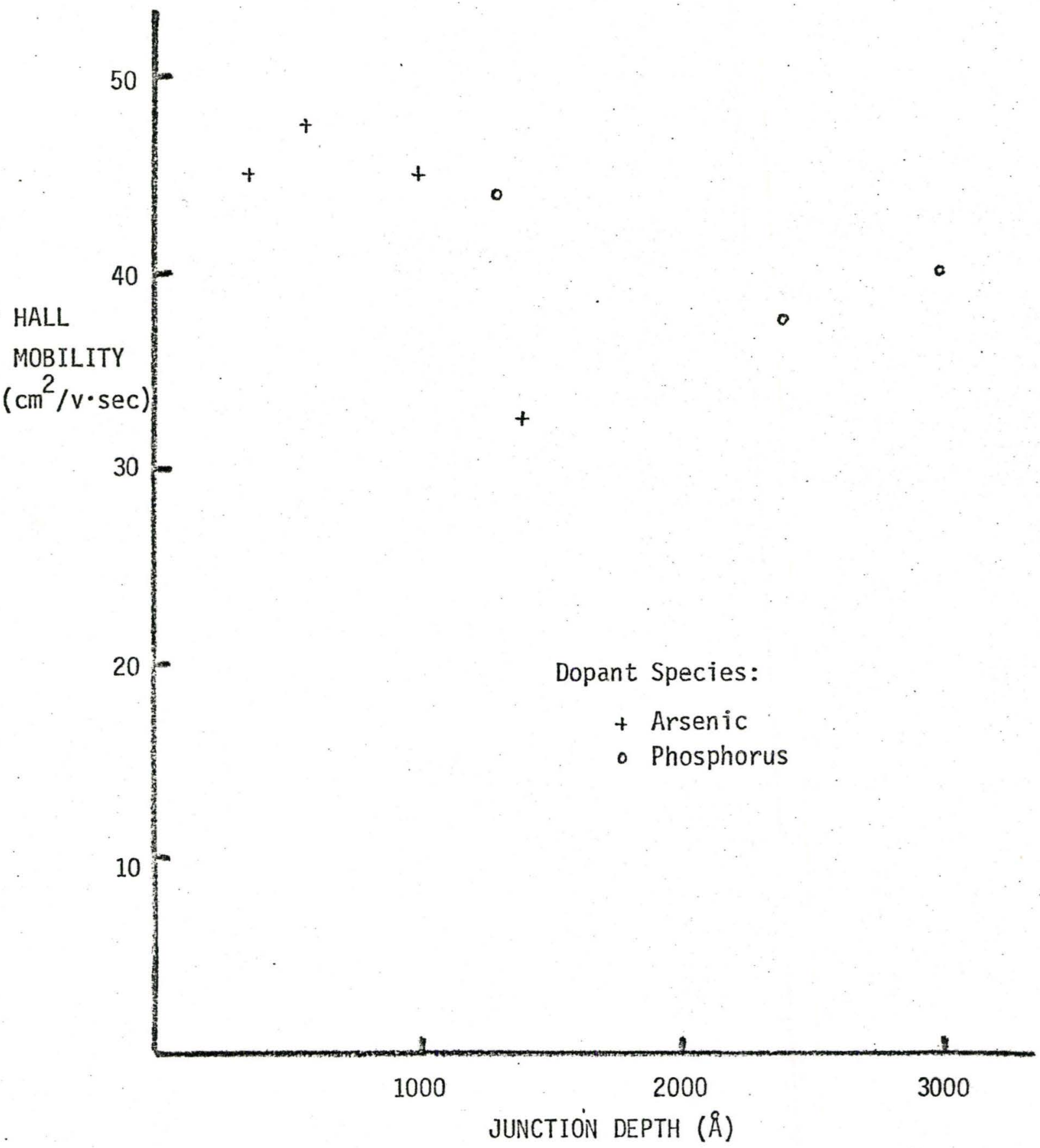

FIGURE 16(b): Hall Mobility vs Junction Depth Samples as in figure 16(a). 


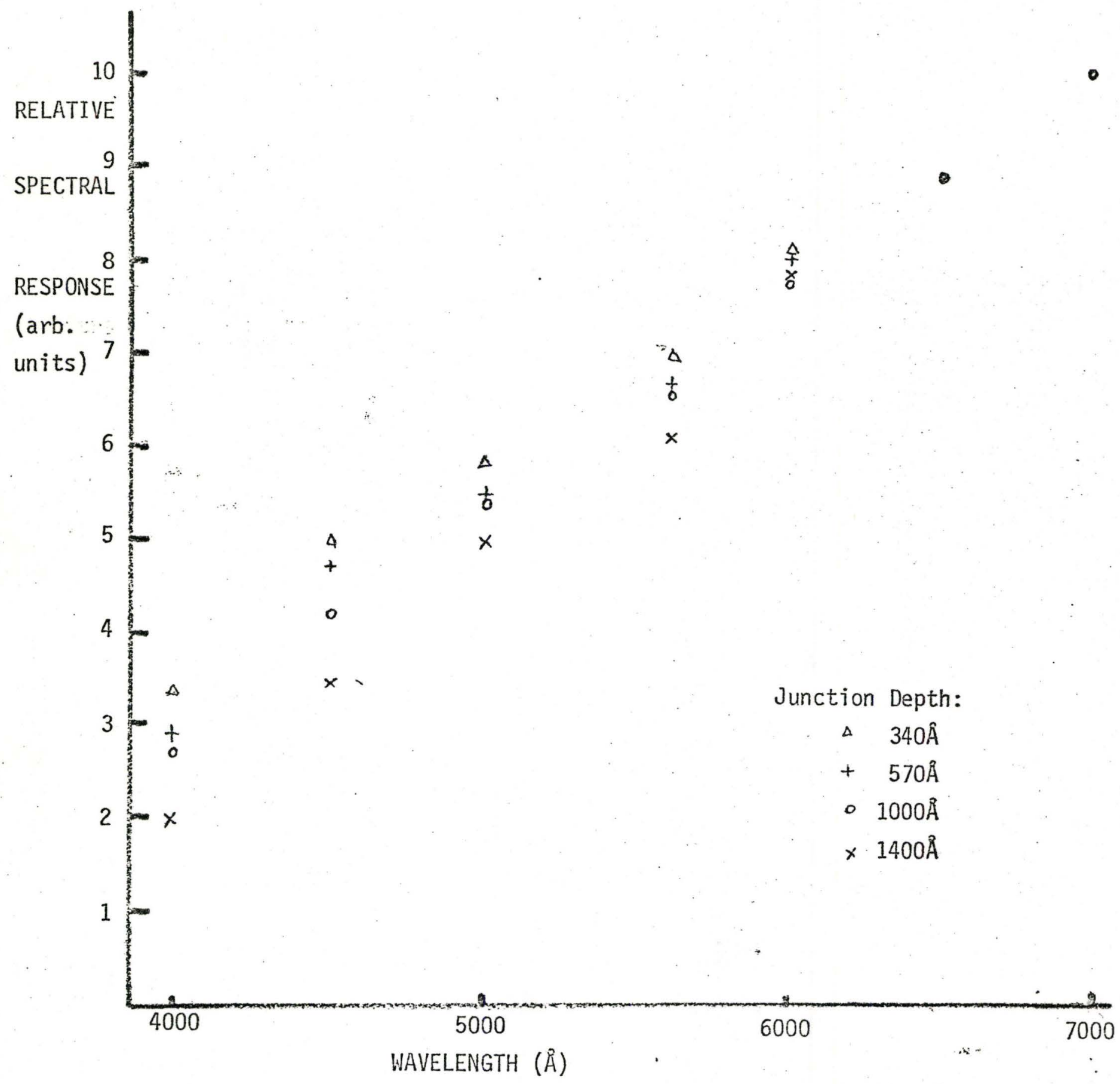

FIGURE 17: Spectral Response at Various Junction Depths Concentration $10^{20} \mathrm{~cm}^{-3}$. Arsenic in $10 \mathrm{ohm}-\mathrm{cm}$ silicon. Implant temperature $20^{\circ} \mathrm{C}$. Anneal temperature $800^{\circ} \mathrm{C}$. Depths from Gibbons et al ${ }^{(7)}$. 


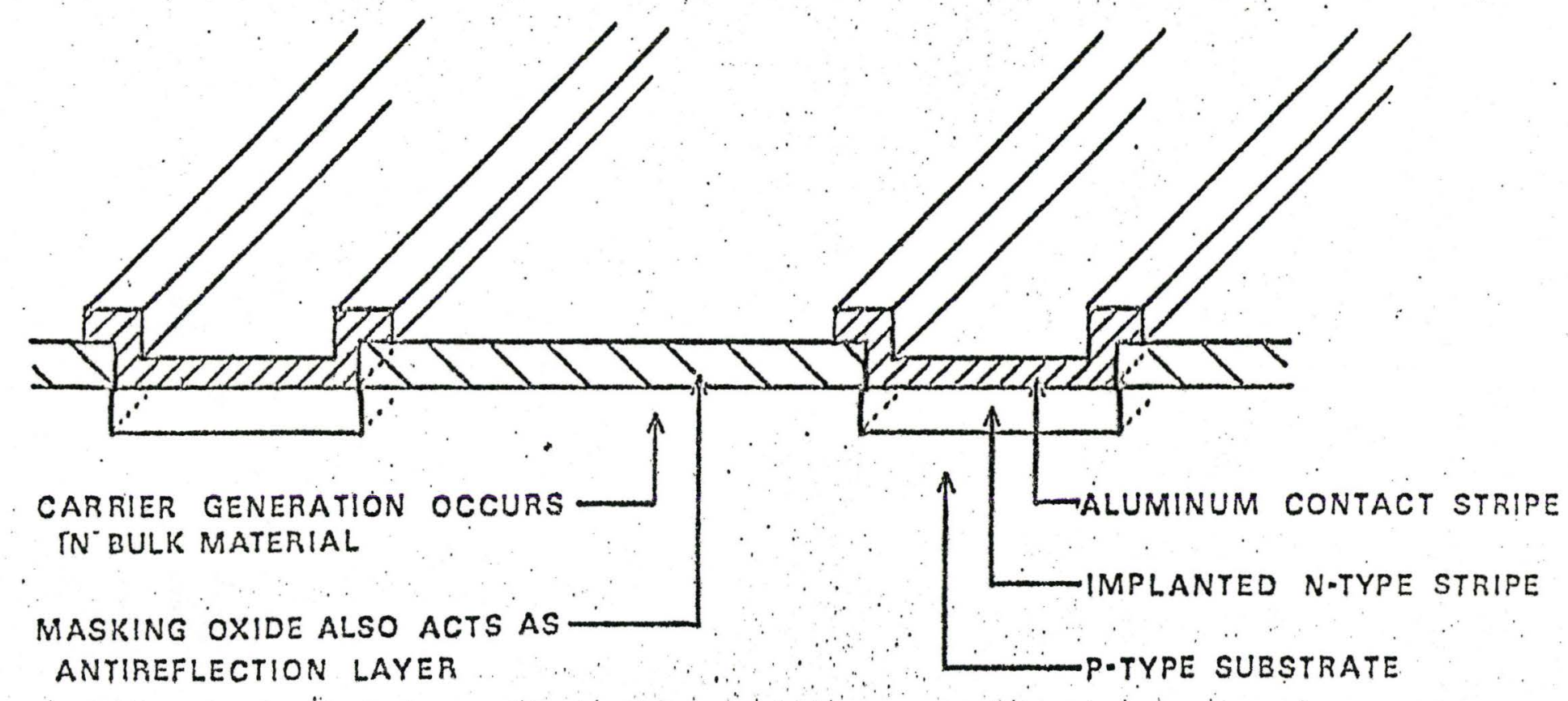
ANTIREFLECTION LAYER 


\section{REFERENCES}

1. J.T. Burri11, W.J. King, S. Harrison, P. McNally, IEEE Trans Elect Dev ED-14, No. 1, 10 (1967)

2. J.P. Ponpon and P. Siffert, Proc 11th Photovoltais Spec Conf, 342 (1975)

3 J. Lindmayer and J. Allison, Proc 9th photovoltaic Spec Conf, 83 (1973)

4. J.J. Loferski, N. Ramaganathan, E.E Crisman and L.Y. Chen, Proc 9th Photovoltaic Spec Conf, 19 (1973)

5 S.M. Sze, Physics of Semiconductor Devices, Wiley-Interscience, 1969

$6 \quad$ R.S. Walker and D.A. Thompson, Nucl Instr and Methods 135, 489 (1976)

7 J.F. Gibbons, W.S. Johnson and S.W. Mylroie, Projected Range Statistics, 2nd edition, Halstead Press, 1975

8 J. Shewchun, K.M. Ghanakar, R. Yager, H.D. Barber and D.A. Thompson, The Rev Sci Instrum 42, 1797 (1971)

9 J.W. Mayer, L. Erikson and J.A. Davies, Ion Implantation in Semiconductors, Academic Press, 1970

10 E. Baldo, F. Cappel1ani, and G. Reste11i, Rad Effects 19, 271 (1973)

11 M. Wolf, Energy Convers 1112, 63 (1971)

12 D.A. Davies, Solid State Electron 13, 229 (1970)

13 J.F. Gibbons, A. E1-Hoshy, K.E. Manchester and F.L. Voge1, App1 Phys Lett $\underline{8.2}, 46$ (1966)

14 J.J. Loferski, "Principles of Photovoltaic Solar Energy Conversion", 25th Annual Proc Power Sources Conf (1972) 